\title{
Obesity induces a phenotypic switch in adipose tissue macrophage polarization
}

\author{
Carey N. Lumeng, ${ }^{1,2}$ Jennifer L. Bodzin, ${ }^{1}$ and Alan R. Saltiel ${ }^{1,3}$ \\ ${ }^{1}$ Life Sciences Institute, University of Michigan, Ann Arbor, Michigan, USA. ${ }^{2}$ Department of Pediatrics and Communicable Diseases and \\ ${ }^{3}$ Departments of Internal Medicine and Physiology, University of Michigan Medical School, Ann Arbor, Michigan, USA.
}

\begin{abstract}
Adipose tissue macrophages (ATMs) infiltrate adipose tissue during obesity and contribute to insulin resistance. We hypothesized that macrophages migrating to adipose tissue upon high-fat feeding may differ from those that reside there under normal diet conditions. To this end, we found a novel $\mathrm{F} 4 / 80^{+} \mathrm{CD} 11 \mathrm{c}^{+}$population of ATMs in adipose tissue of obese mice that was not seen in lean mice. ATMs from lean mice expressed many genes characteristic of M2 or "alternatively activated" macrophages, including Ym1, arginase 1, and Il10. Dietinduced obesity decreased expression of these genes in ATMs while increasing expression of genes such as those encoding TNF- $\alpha$ and iNOS that are characteristic of M1 or "classically activated" macrophages. Interestingly, ATMs from obese $\mathrm{C}$-C motif chemokine receptor $2-\mathrm{KO}(\mathrm{Ccr} 2-\mathrm{KO})$ mice express $\mathrm{M} 2$ markers at levels similar to those from lean mice. The antiinflammatory cytokine IL-10, which was overexpressed in ATMs from lean mice, protected adipocytes from TNF- $\alpha$-induced insulin resistance. Thus, diet-induced obesity leads to a shift in the activation state of ATMs from an M2-polarized state in lean animals that may protect adipocytes from inflammation to an M1 proinflammatory state that contributes to insulin resistance.
\end{abstract}

\section{Introduction}

Recent investigations suggest that obesity gives rise to a state of chronic, low-grade inflammation that contributes to insulin resistance and type 2 diabetes $(1,2)$. Although the tissues and cell types involved in this inflammatory response are not fully understood, there is significant interest in the role of adipose tissue macrophages (ATMs) in the inflammatory changes characteristic of obesity (3). In both humans and rodents, ATMs accumulate in adipose tissue with increasing body weight and their quantity correlates with measures of insulin resistance (4-6). In obese subjects, ATM content is higher in visceral than subcutaneous adipose tissue, consistent with the hypothesis that visceral fat plays a more prominent role in insulin resistance (7). Moreover, weight loss leads to a reduction in both inflammatory markers and ATM content $(4,7)$. ATMs are a prominent source of proinflammatory cytokines such as TNF- $\alpha$ and IL- 6 that can block insulin action in adipocytes, providing a potential link between inflammation and insulin resistance $(6,8)$.

Mouse models have demonstrated that ATMs are both necessary and sufficient for the development of insulin resistance with obesity. Mice with targeted deletions in the genes for monocyte chemoattractant protein-1 $(\mathrm{Mcp} 1 / \mathrm{Ccl} 2)$ and its receptor $\mathrm{C}-\mathrm{C}$ motif chemokine receptor 2 ( $C c r 2$ ) both have decreased ATM content, decreased inflammation in fat, and protection from high-fat diet-induced (HFD-induced) insulin resistance $(9,10)$. Conversely, mice overexpressing MCP-1 have increased numbers of ATMs along with increased insulin resistance $(9,11)$. Moreover, myeloidspecific $\mathrm{KO}$ of $I \kappa B$ kinase $\beta$ (Ikbkb) produced mice with improved insulin sensitivity on HFD (12). Together, these data suggest that

Nonstandard abbreviations used: ATM, adipose tissue macrophage; CCR2, C-C motif chemokine receptor 2; CCR2KO mouse, Ccr2-KO mouse; HFD, high-fat diet; IRS, insulin receptor substrate; MCP-1, monocyte chemoattractant protein-1; ND, normal diet; SVF, stromal vascular fraction.

Conflict of interest: The authors have declared that no conflict of interest exists. Citation for this article: J. Clin. Invest. 117:175-184 (2007). doi:10.1172/JCI29881. both the recruitment and proinflammatory activation of ATMs are required for the development of diabetes with obesity.

While quantitative changes in ATM content with obesity and diabetes are well supported, little is known about the range of ATM function and how this may change with obesity. ATMs are present in moderate quantities in adipose tissue of lean mice in which inflammatory signals are low or nonexistent $(5,6)$, and their role there is unclear. While Ccr2-KO (CCR2KO) and Mcp1-KO mice have lower inflammatory cytokine expression in fat, they retain significant macrophage content within adipose tissue $(9,10)$. This suggests that factors both dependent and independent of the MCP-1/CCR2 axis are involved in macrophage recruitment to fat and, further, that not all ATMs are programmed for proinflammatory signaling.

Macrophages show significant heterogeneity in function, as local environmental factors shape their properties and activation state $(13,14)$. Different stimuli activate macrophages to express distinct patterns of chemokines, surface markers, and metabolic enzymes that ultimately generate the diversity of macrophage function seen in inflammatory and noninflammatory settings. Macrophage activation has been operationally defined across 2 separate polarization states, M1 and M2 $(13,14)$. These states have largely been defined in vitro, and tissue macrophages are likely activated along a continuum between these states in vivo. M1 or "classically activated" macrophages are induced by proinflammatory mediators such as LPS and IFN- $\gamma$. M1 macrophages have enhanced proinflammatory cytokine production (TNF- $\alpha$, IL-6, IL-12) and generate reactive oxygen species such as NO via activation of iNOS (Nos2).

M2 or "alternatively activated" macrophages are generated in vitro by exposure to IL-4 and IL-13 (15). M2 macrophages have low proinflammatory cytokine expression and instead generate high levels of antiinflammatory cytokines IL-10 and IL-1 decoy receptor. Additionally, arginase production is increased in M2polarized macrophages. This enzyme blocks iNOS activity by a variety of mechanisms, including competing for the arginine substrate that is required for NO production (16). Overall, M2 mac- 
A
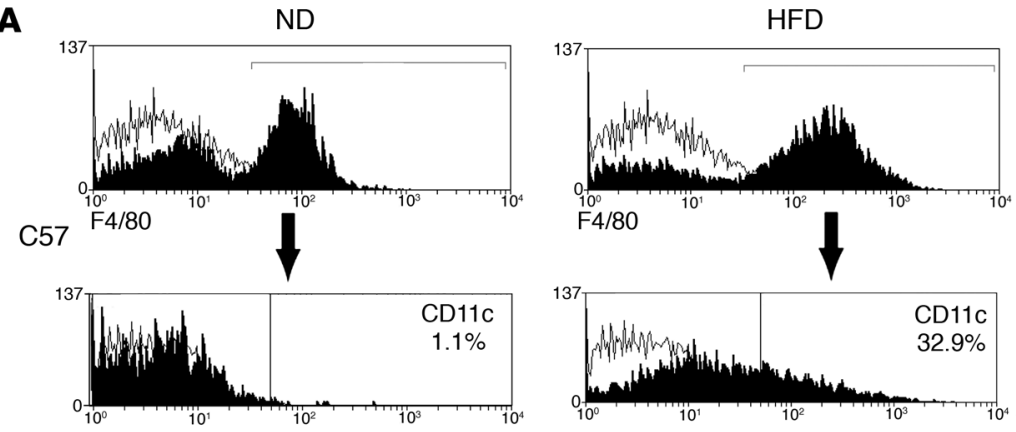

B

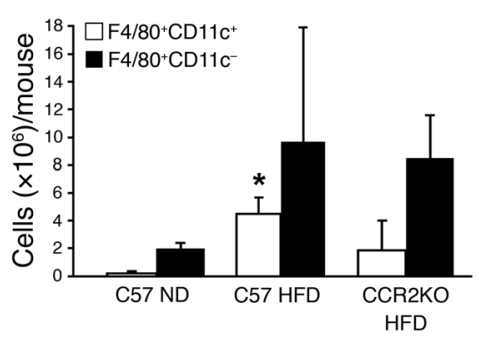

D

ND
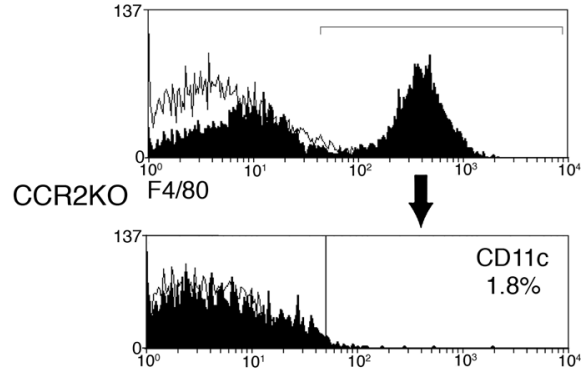

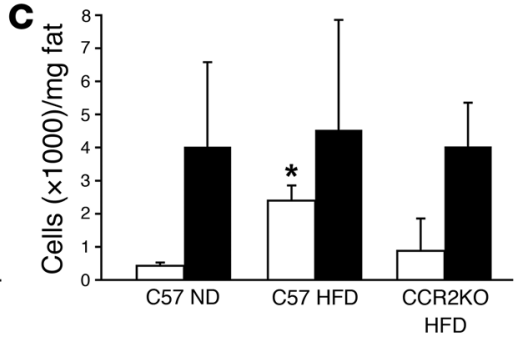

HFD

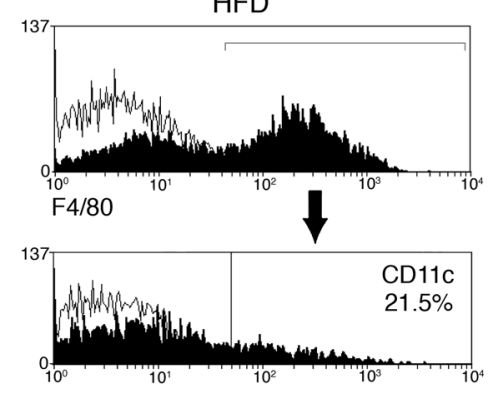

Figure 1

Accumulation of $\mathrm{F} 4 / 80^{+} \mathrm{CD} 11 \mathrm{C}^{+}$ATMs in adipose tissue in obese mice. (A) Analysis of SVF cells for F4/80 and CD11c. Epididymal fat pads from agematched male C57BL/6 (C57) mice on ND or HFD ( $n=3$ mice, each condition) were dissected and separated into adipocyte and SVF populations. SVF cells were stained with antibodies against F4/80, CD11c, and isotype controls (open) and analyzed by flow cytometry. Samples were gated for $\mathrm{F} 4 / 80^{+}$cells and examined for coexpression of CD11c (lower panels). Data from a representative experiment are shown. The percentage of CD $11 \mathrm{c}^{+}$cells within the F4/80+ ATM population is indicated for each condition. (B and C) Quan-

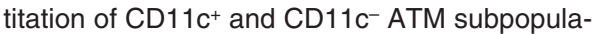
tions in epididymal fat pads. Flow cytometry was used to assess the percentages of $\mathrm{F} 4 / 80^{+} \mathrm{CD} 11 \mathrm{C}^{+}$ and $\mathrm{F} 4 / 80^{+} \mathrm{CD} 11 \mathrm{C}^{-}$ATMs in SVF samples from ND- and HFD-fed C57BL/6 mice and HFD-fed CCR2KO mice ( $n=3-4$ mice per condition). Data are presented as total number of cells per mouse for each ATM subtype (B) and as cell counts normalized to cell number and fat pad weight (C). Data are presented as mean \pm SD ${ }^{*} P<0.05$ versus ND. (D) Analysis of CD11c expression in ATMs isolated from epididymal fat pads from male CCR2KO mice on a C57BL/6 background on ND or HFD. Cell isolation and flow cytometry were performed as described for $\mathbf{A}$. rophages are believed to participate in the blockade of inflammatory responses and in the promotion of tissue repair (13). M2 polarization can occur in the absence of IL-4 or IL-13, suggesting that this state may be induced by several different factors (17). Moreover, recent studies have shown that IL-4-mediated M2 polarization is associated with the activation of transcription factors involved in lipid oxidative metabolism that include PPAR $\gamma$ and PPAR $\gamma$ coactivator $1 \beta$ (PGC-1 $\beta)(18)$.

In mice, distinct monocyte subsets contribute to tissue inflammatory responses $(13,19)$. Noninflamed tissues are populated with macrophages derived from CX3CR1 hiCCR2- monocytes (20). In contrast, acute inflammation increases the levels of CX3CR $1{ }^{\text {lo }} \mathrm{CCR} 2{ }^{+}$Ly- $6 \mathrm{C}^{\text {hi }}$ monocytes, which have a higher capacity for migration into inflamed tissues compared with other monocyte populations (21). This model is consistent with observations that CCR2KO mice have decreased ATM content (10), presumably due to deficient recruitment of CX3CR $1{ }^{\text {lo }} \mathrm{CCR} 2^{+}$ monocytes with retention of the trafficking of CX3CR $1{ }^{\text {hi }}$ CCR2monocytes into adipose tissue.

The qualitative differences between these monocyte/macrophage subtypes in ATMs and obesity are unknown but may be important in understanding the biology of these unique cells and their contribution to diabetes. In this regard, we show here that ATMs undergo a phenotypic switch from an antiinflammatory M2 polarization state to a proinflammatory M1 polarization state upon high-fat feeding, in the process losing their protective capacity.

\section{Results}

$\mathrm{F} 4 / 80^{+} \mathrm{CD} 11 \mathrm{~b}^{+} \mathrm{CD} 11 \mathrm{c}^{+}$macrophages accumulate in fat with diet-induced obesity. As the majority of previous studies have used F4/80 expression as a single marker to identify ATMs, we sought to examine ATM heterogeneity in lean and obese mice using additional known macrophage markers. Epididymal fat tissue plays a significant role in overall metabolism in rodents (22). We thus isolated stromal vascular fraction (SVF) cells from epididymal fat pads excised from male mice fed a normal diet (ND) or HFD and analyzed cells by flow cytometry. ATMs from both lean and obese mice coexpressed F4/80 and CD11b, and the majority of the F4/80+CD11b+ cells also expressed Mac-3 (data not shown). However, there was variation in the amount of CD $11 \mathrm{c}$ expression within the $\mathrm{F} 4 / 80^{+} \mathrm{CD} 11 \mathrm{~b}^{+}$ ATMs. The SVF from lean mice contained $17.8 \% \mathrm{~F} 4 / 80^{+}$cells, consistent with other reports (5). Only a small percentage of these cells coexpressed CD11c $(9.3 \% \pm 7.5 \% ; n=3$ pools of mice) (Figure $1 \mathrm{~A})$. In contrast, obese mice contained increased $\mathrm{F} 4 / 80^{+}$cell content within the SVF, with a significant increase in the percentage of $\mathrm{F} 4 / 80^{+} \mathrm{CD} 11 \mathrm{c}^{+}$cells $\left(38.4 \% \pm 15 \%\right.$ of $\mathrm{F} 4 / 80^{+}$cells; $P=0.04$ versus lean mice). These cells also expressed CD11b. Similar results were seen in leptin-deficient $o b / o b$ mice, with $74 \%$ of the $\mathrm{F} 4 / 80^{+}$cells coexpressing CD11c (data not shown).

The total number of both F4/80 ${ }^{+} \mathrm{CD} 11 \mathrm{c}^{+}$cells $\left(4.52 \pm 1.1 \times 10^{6}\right.$ cells/mouse versus $0.196 \pm 0.16 \times 10^{6}$ cells/mouse; $\left.P=0.021\right)$ and $\mathrm{F} 4 / 80^{+} \mathrm{CD} 11 \mathrm{c}^{-}$cells $\left(1.98 \pm 0.42 \times 10^{6}\right.$ cells/mouse versus $9.69 \pm 8.2 \times 10^{6}$ cells/mouse; $\left.P=0.24\right)$ isolated from epididymal 
fat pads increased in mice fed an HFD compared with lean mice (Figure 1B). Normalizing this data to fat pad weight indicated that there was a 5.5 -fold increase in the content of $\mathrm{F} 4 / 80^{+} \mathrm{CD} 11 \mathrm{c}^{+}$ cells in adipose tissue from HFD-fed compared with ND mice (Figure 1C). In contrast, there was no significant change in the quantity of $\mathrm{F} 4 / 80^{+} \mathrm{CD} 11 \mathrm{c}^{-}$cells in adipose tissue per milligram fat weight between ND and HFD mice. This demonstrates that $\mathrm{F} 4 / 80^{+} \mathrm{CD} 11 \mathrm{c}^{+}$cells are a specific population of ATMs recruited to fat tissue upon HFD exposure.

Previous studies indicated that targeted deletion of the Ccr 2 gene results in decreased macrophage content in adipose tissue and improved insulin sensitivity (10). Thus, CCR2KO mice were also examined for CD11c expression as a complementary mouse model. HFD-fed CCR2KO mice demonstrated a reduction in the content of $\mathrm{F} 4 / 80^{+} \mathrm{CD} 11 \mathrm{c}^{+}$cells in the SVF compared with wild-type obese mice, with $14.4 \% \pm 9.2 \%$ of the $\mathrm{F} 4 / 80^{+}$cells coexpressing CD $11 \mathrm{c}$ $(P=0.08$ versus HFD C57BL/6) (Figure 1D). Normalizing for cell number and fat weight indicated that there was a greater than $50 \%$ reduction in the level of $\mathrm{F} 4 / 80^{+} \mathrm{CD} 11 \mathrm{c}^{+} \mathrm{ATM}$ in the CCR2KO mice (HFD C57BL/6, $2.4 \pm 0.46 \times 10^{3}$ cells/mg versus HFD CCR2KO, $0.88 \pm 0.98 \times 10^{3}$ cells $/ \mathrm{mg}$ ) (Figure $1 \mathrm{C}$ ). The content of total $\mathrm{F} 4 / 80^{+} \mathrm{CD} 11 \mathrm{c}^{+}$cells in fat pads from HFD CCR $2 \mathrm{KO}$ mice was also lower than in obese controls after normalization to cell number (Figure 1B). Similar to what was observed previously (10), adipocyte size was increased in HFD CCR2KO mice compared with control HFD mice (mean 7,933 $\pm 2,754 \mu \mathrm{m}^{2}$ versus $6,704 \pm 2,961 \mu \mathrm{m}^{2}$, $P=0.041)$ and HFD CCR2KO mice were protected from hepatic steatosis (data not shown). Contrary to these observations, however, we noted increased fat pad weight in HFD CCR2KO mice $(2.83 \pm 0.57$ g versus control, $1.41 \pm 0.25 \mathrm{~g} ; P=0.011)$.

Immunofluorescence microscopy confirmed the flow cytometry results; ND SVF cultures contained only F4/80 $+^{+} \mathrm{CD} 11 \mathrm{c}^{-}$cells (Figure $2 \mathrm{~A})$. SVF cells from HFD mice showed a mix of $\mathrm{F} 4 / 80^{+} \mathrm{CD} 11 \mathrm{c}^{+}$ and $\mathrm{F} 4 / 80^{+} \mathrm{CD} 11 \mathrm{c}^{-}$cells. Immunohistochemistry on epididymal fat pads from obese mice localized CD $11 \mathrm{c}^{+}$cells in macrophage clusters surrounding adipocytes (Figure 2B). The CD11c antibody stained a subset of cells in these crownlike structures, while F4/80 stained nearly all of the cells in these clusters. Scattered individual CD11 $\mathrm{c}^{+}$ATMs were observed surrounding adipocytes in what may have been early ATM clusters (Figure 2C). Rare CD11c cells were seen in adipose tissue sections from lean mice.

\section{Figure 2}

CD11c $\mathrm{C}^{+}$ATMs in SVF cultures and in adipose tissue from obese mice. (A) Identification of $\mathrm{F} 4 / 80^{+}$and $\mathrm{CD} 11 \mathrm{C}^{+}$ATMs by immunofluorescence microscopy. Epididymal fat pads from ND and HFD mice were separated into adipocyte and SVF fractions. SVF cells were plated onto glass coverslips and cultured overnight prior to fixation. Cells were stained with antibodies against F4/80 (left) and CD11c (middle) and imaged by confocal microscopy to identify surface markers to confirm the presence of $C D 11 c^{+}$cells only in the SVF from HFD-fed animals. Similar results were obtained for 3 independent sets of cultures. (B) Immunohistochemical localization of $\mathrm{CD} 11 \mathrm{C}^{+}$in adipose tissue. Consecutive sections from epididymal fat pads from obese C57BL/6 mice were stained with anti-F4/80 (left panels) and anti-CD11c antibodies (right panels), followed by colorimetric detection (brown). Sections were counterstained with hematoxylin (blue) and images taken at low $(\times 200)$ and high magnification $(\times 1,000)$. (C) In obese mice, CD11 $\mathrm{c}^{+}$cells were also detected surrounding normal-appearing adipocytes in the absence of crownlike macrophage clusters ( $\times 1,000$ magnification).
Increased inflammatory gene expression in $\mathrm{F} 4 / 80^{+} \mathrm{CD} 11 \mathrm{c}^{+}$ATMs. Because $\mathrm{CD} 11 \mathrm{c}^{+}$cells appear to accumulate in adipose tissue after high-fat feeding, we assessed expression of inflammatory genes in $\mathrm{F} 4 / 80^{+} \mathrm{CD} 11 \mathrm{c}^{+}$ATMs compared with $\mathrm{F} 4 / 80^{+} \mathrm{CD} 11 \mathrm{c}^{-}$ATMs from obese mice. Real-time RT-PCR showed appropriate sorting of the CD11c populations based on expression of integrin, alpha X (Itgax, encoding CD11c) (Figure 3). F4/80 ${ }^{+} \mathrm{CD} 11 \mathrm{c}^{+}$cells overexpressed the inflammatory genes Il6 (IL-6) and Nos2 (iNOS) compared with $\mathrm{F} 4 / 80^{+} \mathrm{CD} 11 \mathrm{c}^{-}$ATMs. Tnfa (TNF- $\alpha$ ) was not differentially expressed between the cell types, while Apoe (apoE) was downregulated in the $\mathrm{F} 4 / 80^{+} \mathrm{CD} 11 \mathrm{c}^{+}$population relative to $\mathrm{F} 4 / 80^{+} \mathrm{CD} 11 \mathrm{c}^{-}$cells.

ATMs from lean mice express markers of alternatively activated macrophages. Given the low level of inflammatory cytokine expression in adipose tissue from lean mice, we examined the ATMs derived from lean mice for known markers of alternatively activated M2

A ND
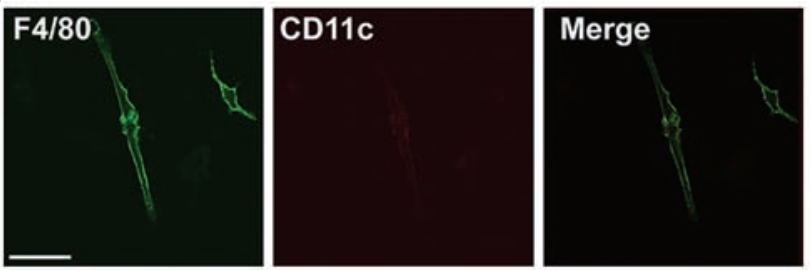

HFD
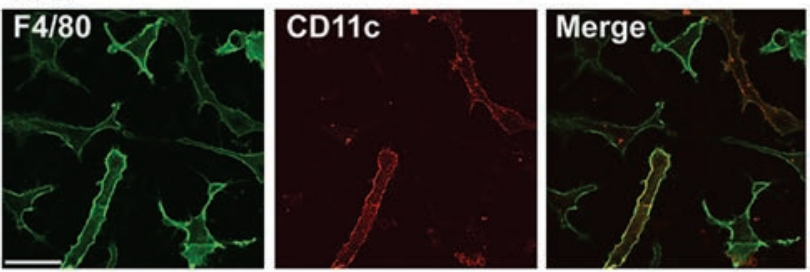

B
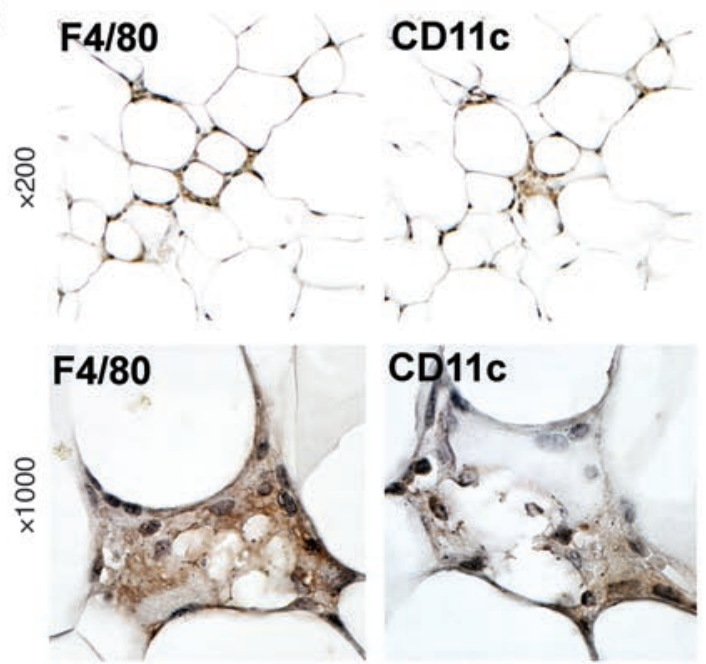

C

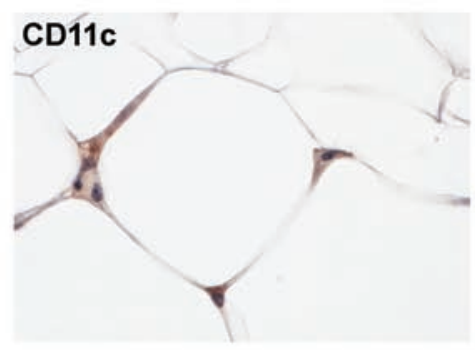




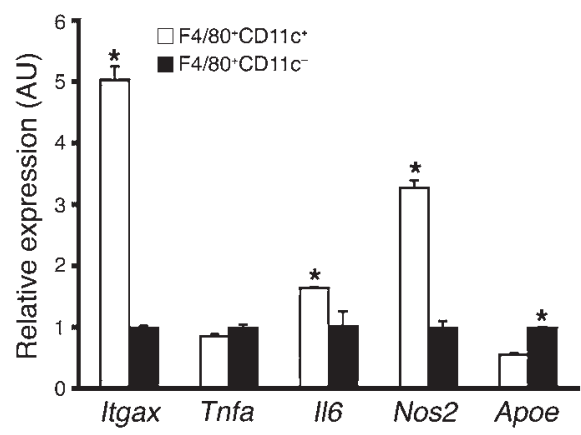

Figure 3

Increased inflammatory gene expression in $\mathrm{F} 4 / 80+\mathrm{CD} 11 \mathrm{C}^{+}$ATMs. SVF cells were isolated from HFD-fed male C57BL/6 mice $(n=3)$ and stained for $\mathrm{F} 4 / 80$ and $\mathrm{CD} 11 \mathrm{c}$. F4/80+CD11 $\mathrm{C}^{+}$and $\mathrm{F} 4 / 80^{+} \mathrm{CD} 11 \mathrm{c}^{-}$cells were isolated by FACS and total RNA isolated. Expression of Itgax (CD11C), Tnfa (TNF- $\alpha$ ), I/6 (IL-6), Nos2 (iNOS), and Apoe (apoE) was analyzed by real-time RT-PCR in $\mathrm{F} 4 / 80^{+} \mathrm{CD} 11 \mathrm{c}^{+}$(white bars) and $\mathrm{F} 4 / 80^{+} \mathrm{CD} 11 \mathrm{c}^{-}$ (black bars) ATMs. Data are expressed as mean \pm SD. ${ }^{*} P<0.05$.

macrophages $(15,23)$. ATMs from lean animals showed increased expression of M2-specific genes Il10 (IL-10), Arg1 (arginase I), Mrc2 (mannose receptor, C type 2), Ym1/Chi3l3 (Ym1/chitinase 3-like 3), and $M g l 1 / 2$ (macrophage galactose $N$-acetyl-galactosamine-specific lectins 1 and 2) compared with the ATMs isolated from HFD mice (Figure 4A). In contrast, expression of proinflammatory genes such as Tnfa and Nos2 was considerably lower in ND ATMs compared with ATMs from obese animals (Figure 4B).

As macrophages make up only a portion of the stromal cells in adipose tissue, we examined expression of some of these genes in unsorted SVF isolates. Similar patterns of gene expression were seen in RNA prepared from SVF cells from lean and obese mice (Figure 4, C and D), with increased $Y m 1$ and $I l 10$ expression in ND mice and increased Tnfa and Nos2 expression in HFD mice.

Since inflammatory macrophage recruitment into fat tissue appears to be partially dependent on CCR2 (10), we hypothesized that ATMs in obese CCR2KO mice might retain properties of M2-polarized macrophages and thus evaluated gene expression in these cells. Indeed, ATMs isolated from obese CCR2KO mice expressed alternatively activated macrophage markers at levels that were similar to those seen in ATMs from lean mice. Furthermore, these were significantly elevated compared with levels in ATMs from obese mice (Figure 4A).

We confirmed gene expression data by examining protein levels in the ATMs under study. Consistent with the RNA expression data, Ym1 was increased in SVF samples from lean compared with obese mice (Figure 4E). Additionally, purification of CD11 b ${ }^{+}$ATMs from SVF samples indicated that $\mathrm{Ym} 1$ is predominantly expressed in ATMs compared with non-macrophage CD11b-cells.

Another characteristic of the alternative macrophage activation state is increased arginase activity (15). Arginase activity was assessed in SVF and adipocyte samples from lean and obese mice. While the activity of this enzyme did not differ between the isolated adipocytes from lean and obese mice, arginase activity was significantly diminished in the SVF fraction after HFD exposure (Figure 4F). This indicates that the arginase/iNOS balance in ATMs from lean animals is skewed toward an immunosuppressive state that changes to a proinflammatory state with obesity (elevated iNOS and repressed arginase activity).
IL-10 protects adipocytes from the deleterious effects of TNF- $\alpha$. The observation that the expression of Il10 is higher in the SVF and ATMs from lean compared with obese mice led us to examine the effects of the cytokine on adipocyte function. To explore the cellular effects of IL-10, we first examined the expression of its receptor. The IL-10 receptor $\alpha$ (IL-10R $\alpha$ ) was detected in adipose tissue by immunoblotting (Figure 5A). Separation of the SVF from adipocytes in lean and obese animals indicated that the IL-10 receptor was expressed primarily in adipocytes, with minimal expression in the SVF (Figure 5B). No significant differences were seen in IL-10R $\alpha$ expression between lean and obese mice.

We next examined IL-10 signaling in differentiated 3T3-L1 adipocytes. STAT3 phosphorylation by the IL-10 receptor has been shown to be required for its antiinflammatory effects (24). Treatment of adipocytes with IL-10 led to the tyrosine phosphorylation of STAT 3 within 5 minutes. This effect peaked at 10 minutes and declined thereafter (Figure 5C). As IL-10 as been shown to activate the PI3K pathway via insulin receptor substrate (IRS) proteins (25), we examined phosphorylation of Akt in response to IL-10. IL-10 treatment of adipocytes produced the rapid serine phosphorylation of Akt (Figure 5C).

IL-10 has a variety of antiinflammatory effects in macrophages and other cell types that includes the antagonism of the actions of TNF- $\alpha$ (26). To examine this in adipocytes, we first analyzed the effect of IL-10 on the secretion of the chemokine MCP-1, thought to be a major attractant for macrophages in states of obesity ( 9 , $11,27)$. IL-10 treatment for 16 hours decreased MCP-1 secretion from adipocytes (Figure 6A). As reports suggest that IL-10 may mediate its antiinflammatory effects by antagonizing activation of NF-KB-mediated gene transcription (28), we examined the effects of IL-10 on TNF- $\alpha$-stimulated NF- $\kappa B$ activity using an $\mathrm{NF}-\kappa \mathrm{B}-$ responsive luciferase reporter gene. While TNF- $\alpha$ induced reporter gene expression, IL-10 had no effect upon this activation (data not shown). This is consistent with other reports that show that IL-10 can alter the transcriptional rate of inflammatory genes independent of NF- $\mathrm{KB}$ activation (29).

We next examined the effects of IL-10 on insulin signal transduction in adipocytes in concert with TNF- $\alpha$. Treatment of cells with TNF- $\alpha$ for 6 hours dramatically reduced the levels of glucose transporter 4 (GLUT4) protein, with a smaller reduction in the level of insulin receptor expression, similar to what has been reported previously (30). IL-10 pretreatment prevented the TNF- $\alpha$-induced downregulation of both proteins (Figure 6B). Additionally, insulin-stimulated IRS1 tyrosine phosphorylation was decreased with TNF- $\alpha$ treatment. This inhibitory effect was prevented by pretreatment with IL-10 (Figure 6C). IL-10 treatment produced no significant changes in TNF- $\alpha$-stimulated IRS1 phosphorylation at Ser307, suggesting that the antagonism of TNF- $\alpha$ action by IL-10 occurs either downstream of or in parallel to reduced tyrosine phosphorylation of IRS1.

To determine whether IL-10 protects adipocytes from the physiological effects of TNF- $\alpha$, we examined insulin-stimulated glucose uptake in 3T3-L1 adipocytes with and without IL-10 pretreatment. Treatment of cells with TNF- $\alpha$ for 3 hours produced a significant, $30 \%-40 \%$ inhibition of insulin-stimulated glucose uptake. Pretreatment of the cells with IL-10 for 24 hours blocked these acute inhibitory effects of TNF- $\alpha$ (Figure 7A). Prolonged (72-hour), lowdose TNF- $\alpha$ treatment increased basal glucose uptake but had no effect on insulin-stimulated levels, consistent with a dramatic upregulation of the glucose transporter GLUT1 under these con- 

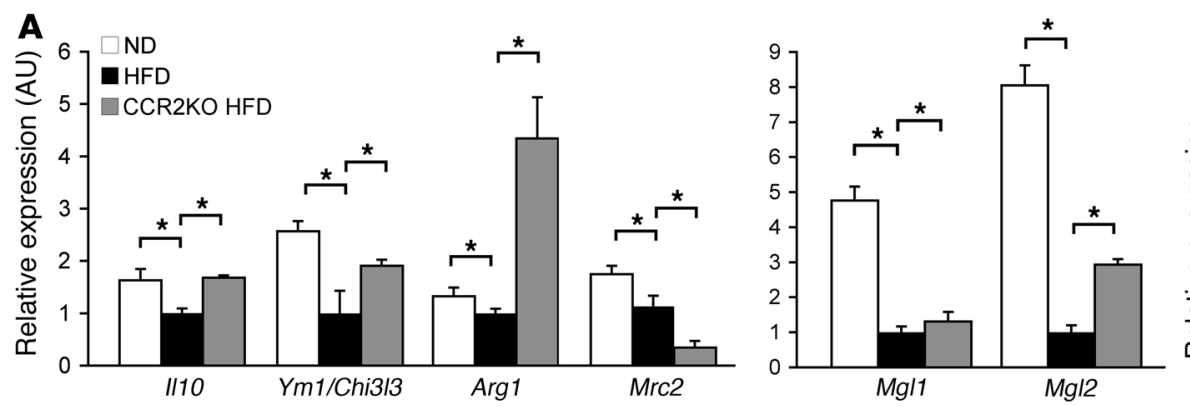

B
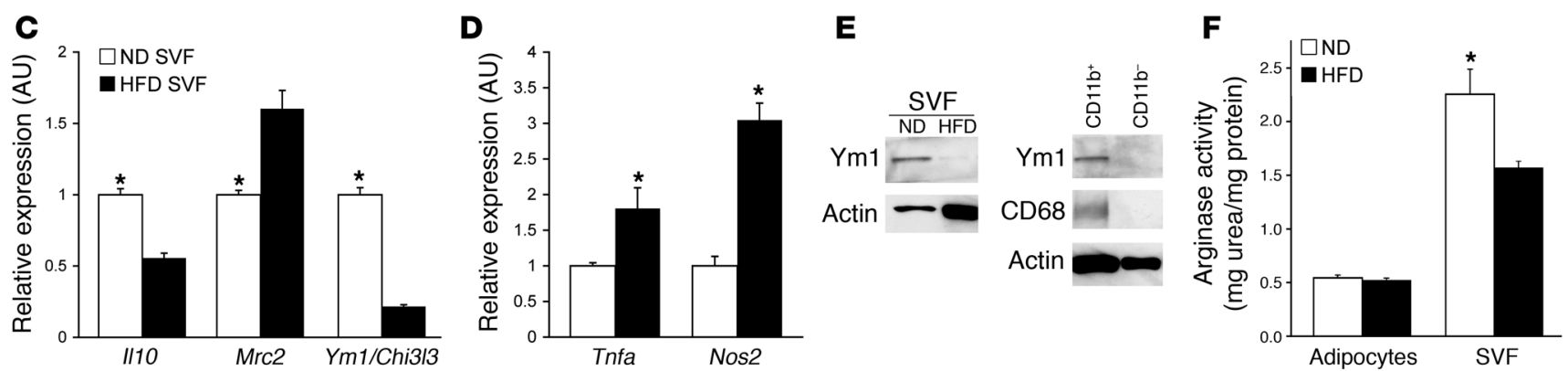

Figure 4

Increased expression of markers of alternatively activated (M2) macrophages in ATMs from lean ND-fed mice. (A and B) Gene expression in ATMs from ND and HFD mice. F4/80+CD11 b+ ATMs were isolated from ND C57BL/6 (white bars), HFD C57BL/6 (black bars), and HFD CCR2KO mice (gray bars) ( $n=3$ pools of mice for each) and analyzed by real-time RT-PCR for expression of M2 macrophage-specific genes (A) and proinflammatory genes $(\mathbf{B})$. Data are expressed as mean \pm SD. ${ }^{*} P<0.05$. (C and D) SVF was isolated from ND (white bars) and HFD (black bars) mice ( $n=2-3$ mice per condition) and analyzed by real-time RT-PCR for expression of M2 macrophage markers (C) and proinflammatory genes (D). (E) Ym1 protein expression in the SVF. Lysates from SVF isolated from ND and HFD mice were immunoblotted for Ym1 (left). CD11 b+ ATMs were separated from CD11b- cells in the SVF and lysates prepared for immunoblotting, which demonstrated Ym1 expression in the macrophage fraction (right). Macrophage marker CD68 controlled for the purification protocol. Similar results were obtained in a duplicate experiment. (F) Arginase activity in adipose tissue from ND and HFD mice. Epididymal fat pads from ND- (white bars) and HFD-fed (black bars) mice were separated into adipocyte and SVF fractions and lysates prepared. Arginase activity was assessed by an assay of urea production from arginine substrate and was normalized to protein concentration. Reactions were performed in triplicate. Data are expressed as mean \pm SD. ${ }^{\star} P<0.05$. Similar results were obtained for 3 separate sets of mice.

ditions (31). IL-10 blocked these effects of TNF- $\alpha$ and maintained cells in an insulin-sensitive state (Figure 7B). Moreover, insulinstimulated glucose uptake was dramatically enhanced in cells chronically treated with IL-10 compared with untreated cells.

\section{Discussion}

Recent data suggest that obesity may represent a state of chronic, low-grade inflammation and that overnutrition is associated with the infiltration of adipose tissue by inflammatory cells (2). Although the precise cell types involved in this process remain uncertain, evidence is mounting that implicates ATMs as a significant contributor to inflammation in obesity and a mediator of insulin resistance $(3,9,32)$. Because the properties of ATMs are not well characterized, we performed a detailed examination of ATM subtypes and their gene expression in obese and lean mice. Based on the wide range of functions that macrophages display in normal and inflamed tissues (33), we hypothesized that ATMs are differentially activated depending on the degree of adiposity and, further, that in addition to quantitative differences, qualitative differences exist between ATMs in lean and obese animals.

We report here that ATMs isolated from white adipose tissue from lean animals express hallmarks of polarization toward an alternatively activated state (M2), suggesting a potentially beneficial function of these cells. M2 polarization has been described in tumor-associated macrophages and parasitic infections and is believed to regulate tissue repair and prevent excess inflammation $(15,34)$. The markers of M2-polarized macrophages are still being described but include expression of the chitinase family member Ym1, the antiinflammatory cytokine IL-10, arginase, and surface lectins Mgl1 and Mgl2 $(15,23)$. The genes encoding all of these proteins were overexpressed in ATMs from lean compared with obese mice. Moreover, ATMs from obese CCR2KO mice, which display significantly lower inflammatory gene expression compared with their wild-type counterparts, express M2 markers at levels comparable to those in lean mice. This observation is consistent with the evidence that resident tissue macrophages in normal conditions are derived from CCR2- monocytes, while macrophages recruited to sites of inflammation are derived from CCR2 $2^{+}$monocytes (20).

In the current paradigm of macrophage polarization, the properties of M2 macrophages contrast with the proinflammatory activities of classically activated M1 macrophages. One important difference between these polarization states involves the balance between arginase and iNOS activities. Arginase and iNOS both utilize L-arginine as a substrate. However, while iNOS generates reactive NO species with microbicidal and proinflammatory effects important in immune responses, arginase competes with iNOS for arginine as a substrate and generates L-ornithine, an important precursor for proline that enhances collagen biosynthesis (16). 


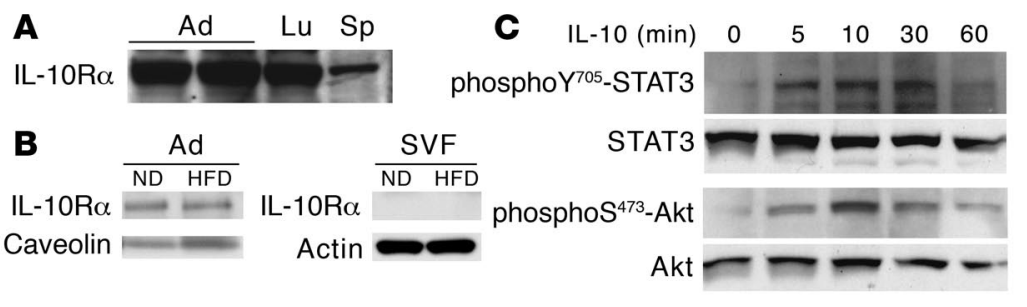

\section{Figure 5}

IL-10 signaling in adipocytes. (A) Expression of IL-10 receptor in adipose tissue. Immunoblots of lysates from adipose tissue (Ad), lung (Lu), and spleen (Sp) from mice probed with IL-10 receptor $\alpha(\mathrm{IL}-10 \mathrm{R} \alpha)$ antibodies. (B) Expression of IL-10 receptor in adipocytes and not the SVF from adipose tissue. Epididymal fat pads from ND- and HFD-fed mice were collected and separated into SVF and adipocyte fractions. Lysates were prepared and immunoblotted with anti-IL-10 receptor antibodies and loading controls. (C) IL-10 treatment of adipocytes activates STAT3 and Akt. Differentiated 3T3-L1 adipocytes were stimulated with IL-10 $(20 \mathrm{ng} / \mathrm{ml})$ for the indicated times and lysates prepared. Immunoblots were probed with antibodies against phosphoY705. STAT3 and phosphoS ${ }^{473}$-Akt and STAT3 and Akt as loading controls. Experiments were repeated twice, and results of a representative experiment are shown.

Based both on gene expression analysis and direct measurement of activity, ATMs from lean mice exhibit enhanced arginase activity compared with obese mice. This balance in favor of arginase may play a critical role in repressing the generation of $\mathrm{NO}$ and other reactive oxygen species by iNOS and thus maintain adipocyte function and promote tissue repair and remodeling.

The dramatic differences in IL-10 expression in lean compared with obese ATMs imply an important role for this cytokine as a homeostatic regulator in insulin sensitivity. Acute IL-10 infusion was shown to improve insulin sensitivity in whole animals (35), suggesting that this molecule may balance the effects of proinflammatory cytokines such as TNF- $\alpha$. In humans, circulating IL-10 levels correlate with markers of improved insulin sensitivity (36), and IL-10 levels increase along with insulin sensitivity after exercise (37). Polymorphisms in the IL-10 promoter associated with low IL-10 expression are correlated with increased obesity and insulin resistance (38). Additionally, adiponectin has been shown to induce IL-10 expression in human leukocytes (39). Studies have also shown that in obese humans and rodents, both adipocyte and SVF compartments from adipose tissue are significant sources of IL-10 (40). As levels of proinflammatory cytokines are increased in obesity, this observation is consistent with the hypothesis that a balance

\section{Figure 6}

IL-10 prevents the effects of TNF- $\alpha$ on adipocytes. (A) IL-10 decreases MCP-1 secretion by adipocytes. 3T3-L1 adipocytes were treated with media with or without IL-10 $(20 \mathrm{ng} / \mathrm{ml})$ for 16 hours. Conditioned media was then removed and assayed for MCP-1 levels by ELISA. $n=5$ independent samples per condition. Data are expressed as mean \pm SD. (B) IL-10 protects adipocytes from TNF- $\alpha$-induced downregulation of insulin receptor and glucose transporter 4 (GLUT4) expression. 3T3-L1 cells were treated with or without IL-10 for 24 hours prior to treatment with or without TNF- $\alpha(17 \mathrm{ng} / \mathrm{ml}$ for 6 hours). Lysates were prepared and immunoblots probed with antibodies against the insulin receptor (IR) and GLUT4. (C) IL-10 maintains IRS levels despite treatment with TNF- $\alpha$. Adipocytes were treated as described for B and lysates examined for IRS1 tyrosine phosphorylation induced by insulin (INS; $100 \mathrm{nM}$ for 5 minutes) after immunoprecipitation of IRS1. IRS serine phosphorylation at Ser307 was evaluated using specific antibodies. exists between proinflammatory and antiinflammatory factors that governs adipocyte function.

In vitro studies described here show that IL-10 protects against TNF- $\alpha$-dependent insulin resistance in adipocytes. The mechanism underlying this effect remains uncertain. In macrophages, IL-10 attenuates TNF- $\alpha$ inflammatory signals via activation of STAT3 (24) and modulation of inflammatory gene transcription rates (29). We have not observed changes in TNF- $\alpha$-stimulated NF- $\kappa$ B activation with IL-10 in adipocytes, although we did observe increased PI3K signaling with the cytokine. This observation agrees with previous reports that IL-10 can activate PI3K pathways via IRS (25) and suggests a possible mechanism by which IL-10 can antagonize the deleterious effects of TNF- $\alpha$ on insulin signaling in adipocytes.

Obesity leads to a shift in ATM phenotype exemplified by increased Tnfa and Nos2 expression, both characteristically activated in classically activated M1 macrophages (4-6). We have identified a unique subset of ATMs present only in obese animals that express $\mathrm{F} 4 / 80^{+} \mathrm{CD} 11 \mathrm{~b}^{+} \mathrm{CD} 11 \mathrm{c}^{+}$. These cells overexpress inflammatory genes compared with $\mathrm{F} 4 / 80^{+} \mathrm{CD} 11 \mathrm{~b}^{+} \mathrm{CD} 11 \mathrm{c}^{-} \mathrm{ATM}$ and are the major ATM population that accumulates in fat with diet-induced obesity. These studies indicate a previously uncharacterized diversity within the ATM population in obese mice that may have important functional consequences.

CD11c is a marker for DCs, which primarily function in phagocytosis, immune surveillance, and antigen presentation. $\mathrm{F} 4 / 80^{+} \mathrm{CD} 11 \mathrm{c}^{+} \mathrm{DCs}$ have been termed interstitial dendritic cells; they were recently described in a kidney network that is believed to participate in immune surveillance (41). How these DCs participate in inflammatory signals in adipose tissue is unknown. It is possible that DC activation is critical to the coordination of inflammatory events within fat tissue. An important role for DCs in obese adipose tissue is supported by the decreased expression of $\mathrm{MHC}$ class II genes in CCR2 KO mice relative to controls (10). More-
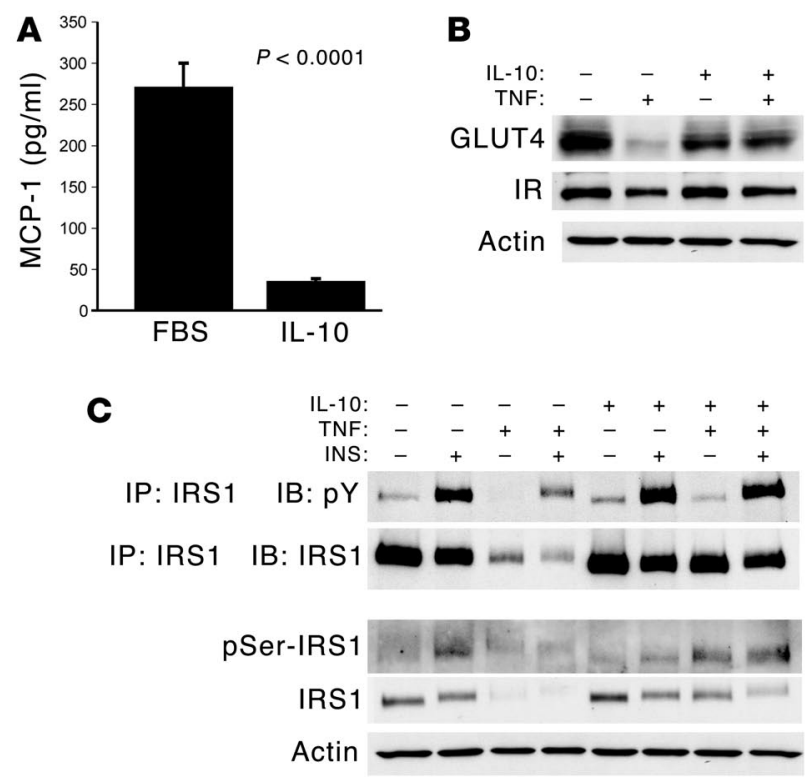
A

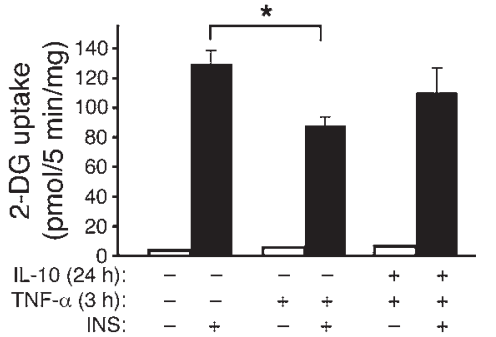

B
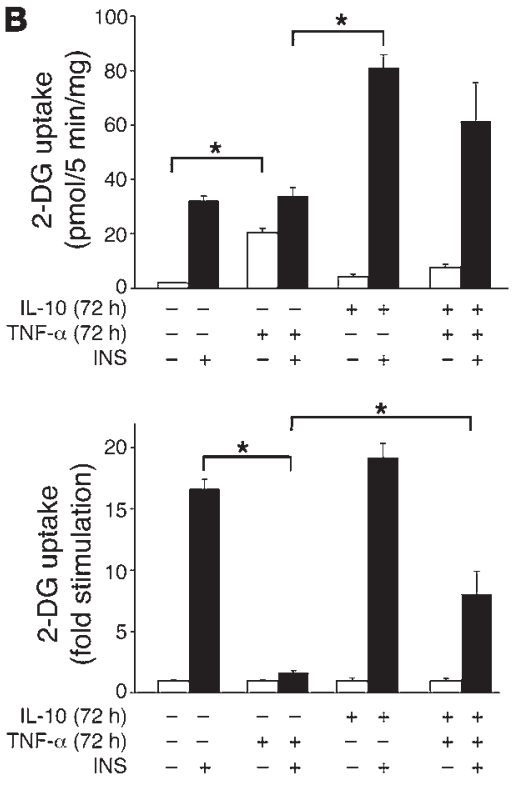

Figure 7

IL-10 prevents the effects of TNF- $\alpha$ on blocking insulinstimulated glucose uptake in adipocytes. (A) Pretreatment of adipocytes with IL-10 blocks TNF- $\alpha$ effects on glucose uptake. 3T3-L1 adipocytes were treated with IL-10 $(20 \mathrm{ng} / \mathrm{ml})$ for 24 hours prior to treatment with TNF- $\alpha$ (17 $\mathrm{ng} / \mathrm{ml})$ for 3 hours. 2-Deoxyglucose (2-DG) uptake was assessed after 30 minutes without (white bars) or with (black bars) insulin (100 nM) stimulation. Data are expressed as mean \pm SD of triplicate experiments repeated 3 times. ${ }^{*} P<0.05$. (B) Insulin-stimulated glucose uptake in adipocytes chronically treated with IL-10 and TNF- $\alpha$. Differentiated 3T3-L1 adipocytes were treated with low-dose TNF- $\alpha(3 \mathrm{ng} / \mathrm{ml})$ for 72 hours in the presence or absence of IL-10 (20 ng/ml). After insulin stimulation (black bars), 2-DG uptake (upper panel) and fold change in glucose uptake (lower panel) were assessed, and the results demonstrated that IL-10 blocks the effects of TNF- $\alpha$. Data are expressed as mean \pm SD of triplicate experiments repeated 2 times. ${ }^{*} P<0.05$. over, we have observed an increased expression of MHC class II genes in ATMs specifically recruited to adipose tissue with HFD (42). These data suggest that DC-coordinated immunity may be crucial to the inflammatory events in adipose tissue that occur with obesity. Why such DCs are activated and what antigens they respond to is currently unknown.

Examining ATM infiltration into adipose tissue in the context of monocyte and macrophage heterogeneity leads us to propose a model for ATM biology that incorporates the diversity of these cells (Figure 8). In lean animals, resident macrophages are polarized toward an M2 state (high IL-10 and arginase levels) derived from CCR2- monocytes that help maintain normal adipocyte function, perhaps by promoting tissue repair and angiogenesis in adipose tissue. Nutrient excess leads to adipocyte expansion, with increased secretion of monocyte chemoattractants that recruit inflammatory type CCR2 ${ }^{+}$monocytes to fat, where they differentiate into M1-polarized activated macrophages and CD11 $\mathrm{c}^{+} \mathrm{DCs}$. Alternatively activated M2 macrophages may be able to partially prevent the activation and accumulation of these classically activated M1 macrophages $(43,44)$, and the secretion of IL-10 helps protect adipocytes against the deleterious effects of TNF- $\alpha$ and related cytokines. However, with increasing adiposity, increased proinflammatory signals, continued recruitment of M1-polarized $\mathrm{CCR} 2^{+}$monocytes, and accumulation of CD $11 \mathrm{c}^{+}$ATMs all contribute to overwhelm the protective effects of M2 macrophages, leading to a dominant role for M1-polarized, classically activated macrophages that generate high TNF- $\alpha$, IL- 6 , and NO production. This model explains observations in obese CCR2KO and Mcp1/ Ccl2-KO mice that retain a population of ATMs with decreased inflammatory capacity $(9,10)$. We suspect that these KOs are deficient in the recruitment of CCR $2^{+}$monocytes during inflammation in fat tissue, while the trafficking of CCR2- monocytes with M2 polarization remains intact. Studies aimed at determining whether enhancing M2 polarization in ATMs can block dietinduced insulin resistance will be required in order to test this model. One limitation of the data leading to this model is that they are largely based on flow cytometric analysis of isolated SVF populations after collagenase digestion. This method of separation is an efficient one but may not fully capture all stromal cells from adipose tissue (5).

How diet-induced obesity leads to a change from M2 to M1 polarization is currently unknown, but the mechanism is likely multifactorial. Our data suggest that the MCP-1/CCR2 axis contributes to this polarization. We propose 2 potential models for this qualitative change in ATM activation: (a) Obesity may lead to an increase in the level of $\mathrm{Ly}-6 \mathrm{C} \mathrm{Ch}^{\mathrm{CCCR}} 2^{+}$circulating monocytes that are primed for activation along an $\mathrm{M} 1$ polarization pattern. Factors such as MCP-1, TNF- $\alpha$, and free fatty acids that activate TLR4 (45) may combine to influence this activation pattern as these monocytes enter adipose tissue. This model is supported by observations that obesity is associated with changes in activation state of circulating monocytes toward a more proinflammatory phenotype $(46,47)$. (b) Alternatively, obesity may change ATMs in adipose tissue from an M2 toward an M1 phenotype. Macrophages are reported to have the potential to switch from one polarization state to another depending upon environmental stimuli (48). However, this model depends upon a slow turnover of ATMs. Studies involving pulse labeling macrophages in vivo indicated that ATMs are largely replaced by 8 weeks in HFD-fed mice (42). Additionally, we have observed that the ATMs recruited to adipose tissue in HFD-fed mice overexpress Ccr2 and other proinflammatory mediators. These observations are consistent with the first hypothesis, according to which obesity leads to the recruitment of M1-polarized macrophages that gradually replace M2-polarized cells, which represents the default pathway of activation under lean conditions.

Our study frames ATM biology within the context of other known models of inflammation and macrophage recruitment. It may be possible to decrease inflammatory signals in adipose tissue by modifying ATMs to retain an M2 polarization or by converting M1 polarized macrophages to M2. Increasing IL-10 levels may represent one mechanism through which this could occur, since chronic IL-10 secretion can suppress classically activated M1 macrophages (49). Future investigations will focus on identifying 


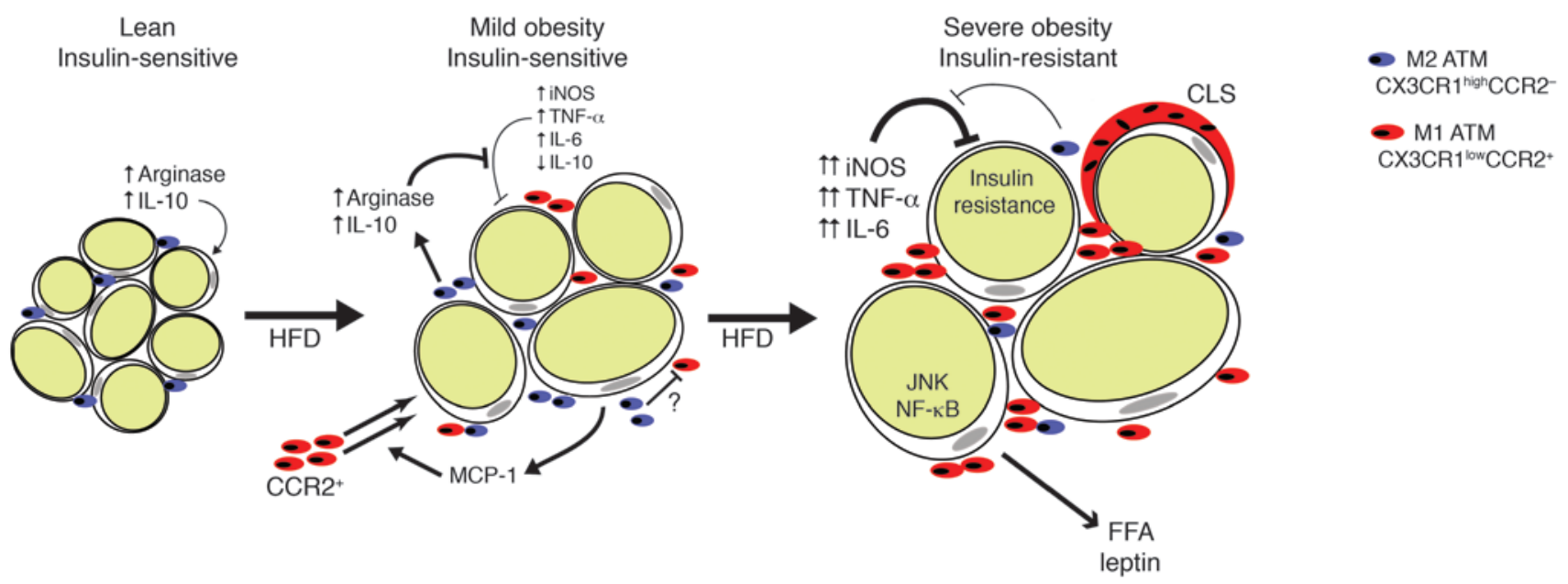

Figure 8

Proposed model for ATM polarization and its function in adipose tissue with progressive obesity. In lean, insulin-sensitive states, ATMs are polarized toward an M2 state with IL-10 and arginase expression. Early during HFD treatment, adipocytes undergo hypertrophy, releasing chemokines that induce recruitment of M1-polarized ATMs with low IL-10 expression and increased iNOS and TNF- $\alpha$ production. In these early stages of mild obesity with retained insulin sensitivity, M2-polarized resident ATMs are able to partially protect adipocytes from these inflammatory factors and may block M1 polarization. With increased adiposity, recruited CCR2+ ATMs form crownlike structures (CLS) and overwhelm the protective effects of M2 macrophages, leading to a dominant role for TNF- $\alpha$ and iNOS. These factors generate insulin resistance in adipocytes, activate JNK and $\mathrm{NF}-\mathrm{KB}$, alter adipokine secretion, and lead to excess circulating levels of free fatty acids due to adipocyte lipolysis and impaired lipogenesis.

factors that trigger the phenotypic switch of macrophage polarization in fat and whether these changes in polarization state are limited to fat or are generalizable to macrophages in other tissues.

\section{Methods}

Materials and reagents. For immunoblots, anti-phosphotyrosine (4G10) and IRS1 antibodies were purchased from Upstate USA Inc. $\beta$-Actin monoclonal antibody was obtained from Sigma-Aldrich. GLUT4 antibodies were obtained from Alpha Diagnostics International. STAT3, phosphotyrosineSTAT3, Akt, and phospho-Akt antibodies were purchased from Cell Signaling Technology. Mouse recombinant TNF- $\alpha$ and IL-10 were obtained from Sigma-Aldrich. Anti-CD68, anti-IL-10 receptor $\alpha$ antibodies, and MCP-1 ELISA kits were purchased from R\&D Systems. Anti-F4/80 antibodies were from Abcam. Alexa Fluor 488-conjugated CD11b and unconjugated $\mathrm{CD} 11 \mathrm{c}$ and $\mathrm{CD} 11 \mathrm{~b}$ antibodies were from AbD Serotec. PE-conjugated anti-Mac-3, PE/Cy5-conjugated anti-F4/80, APC-conjugated anti-CD11c, and isotype antibodies were purchased from eBioscience. Anti-Ym1 antibodies were purchased from StemCell Technologies.

Animals and animal care. Male C57BL/6 mice were rendered insulin resistant by feeding an HFD consisting of $45 \%$ of calories from fat (D12451; Research Diets Inc.) starting at 8 weeks of age for 20 weeks or indicated times. Control mice were fed a standard diet consisting of $4.5 \%$ fat (5002; LabDiet). $o b / o b^{J}$ mice were obtained from The Jackson Laboratory. CCR2KO mice on a C57BL/6 background were kindly provided by S. Kunkel (University of Michigan). Animals were housed in a specific pathogenfree facility with a 12-hour light/12-hour dark cycle and given free access to food and water. All animal use was in compliance with the Institute of Laboratory Animal Research Guide for the Care and Use of Laboratory Animals and approved by the University Committee on Use and Care of Animals at the University of Michigan.

Cell culture. 3T3-L1 fibroblasts were propagated and differentiated into adipocytes as described previously (50). Adipocytes were used in experiments $8-10$ days after differentiation. Adherent SVF cells were cultured on plastic or glass coverslips in DMEM supplemented with $10 \%$ endotoxin- free FBS. For signaling experiments, the cells were starved overnight in $0.5 \%$ serum media prior to stimulation with IL-10. For chronic treatment with IL-10 $(20 \mathrm{ng} / \mathrm{ml})$ and TNF- $\alpha(3 \mathrm{ng} / \mathrm{mL})$, adipocyte media was replaced with fresh media every 24 hours.

SVF isolation and ATM purification. Epididymal fat pads from male C57BL/ 6 mice fed an ND or HFD were excised and minced in PBS with calcium chloride and $0.5 \%$ BSA. Tissue suspensions were centrifuged at $500 \mathrm{~g}$ for 5 minutes to remove erythrocytes and free leukocytes. Collagenase (Sigma-Aldrich) was added to $1 \mathrm{mg} / \mathrm{ml}$ and incubated at $37^{\circ} \mathrm{C}$ for 20 minutes with shaking. The cell suspension was filtered through a $100-\mu \mathrm{m}$ filter and then spun at $300 \mathrm{~g}$ for 5 minutes to separate floating adipocytes from the SVF pellet. To ensure proper isolation, adipocyte fractions were examined by microscopy before and after plating on plastic to detect adherent cells. Samples were digested until adipocyte fractions were free of adherent cells by these 2 quality-control methods to ensure recovery of the majority of the SVF population.

For cell culture, the pellet containing the SVF cells was resuspended in growth media for further experiments. For flow cytometry, the SVF pellet was resuspended in $0.5 \mathrm{ml} \mathrm{RBC} \mathrm{Lysis} \mathrm{Buffer} \mathrm{(eBioscience)} \mathrm{and} \mathrm{incubated}$ for 5 minutes prior to resuspension in sorting buffer (PBS with $0.5 \%$ endotoxin-free FBS, 2 mM EDTA, and $25 \mathrm{mM}$ HEPES) at a concentration of $10^{7}$ cells $/ \mathrm{ml}$. Cells were incubated with Fc Block (BD Biosciences) prior to staining with conjugated antibodies for 15 minutes at $4{ }^{\circ} \mathrm{C}$ followed by 2 washes in 10x excess of sorting buffer. Cells were resuspended in sorting buffer supplemented with DAPI and then analyzed by FACS (FACSAria; BD Biosciences). Viable cells were sorted directly into RNA lysis buffer for RNA extraction. ATMs were identified by coexpression of F4/80 and CD11b.

Isolation of $\mathrm{CD}_{11} \mathrm{~b}^{+}$cells from SVF isolates was performed by magnetic immunoaffinity isolation with anti-CD11b antibodies conjugated to magnetic beads (MACS; Miltenyi Biotec). Cells were isolated using positive selection columns prior to preparation of whole-cell lysates.

Immunofluorescence staining. For immunofluorescence, SVF cells were plated onto glass coverslips for 2 hours, and nonadherent cells were removed by 3 washes with PBS. After 24 hours, the cells were fixed by incubation with 
$10 \%$ formalin for 20 minutes at room temperature. Cells were blocked in $2 \%$ BSA in PBS and incubated with primary antibodies diluted in blocking buffer. Alexa Fluor 488-conjugated secondary antibodies were incubated at a concentration of $2 \mathrm{mg} / \mathrm{ml}$. Coverslips were mounted on slides with VECTASHIELD (Vector Laboratories) and imaged on a confocal fluorescence microscope (Olympus FV300).

Real-time RT-PCR. RNA extraction was performed with an RNeasy kit (QIAGEN). RT reactions were performed using standard methods (Stratagene) and real-time PCR analysis was performed using SYBR Green normalized to GAPDH (ABI Prism 7200 Sequence Detection System; Applied Biosystems). PCR primers used were: Apoe For, 5'-CTGACAGGATGCCTAGCCG-3'; Apoe Rev, 5'-CGCAGGTAATCCCAGAAGC-3'; Arg1 For, 5'-CTCCAAGCCAAAGTCCTTAGAG-3'; Arg1 Rev, 5'-AGGAGCTGTCATTAGGGACATC-3'; Chi3l3 For, 5'-AGAAGGGAGTTTCAAACCTGGT-3'; Chi3l3 Rev, 5'-GTCTTGCTCATGTGTGTAAGTGA-3'; Gapdh For, 5'-TGAAGCAGGCATCTGAGGG-3'; Gapdh Rev, 5'-CGAAGGTGGAAGAGTGGGAG-3'; Il10 For, 5'-GCTCTTACTGACTGGCATGAG-3'; Illo Rev, 5'-CGCAGCTCTAGGAGCATGTG-3'; Itgax For, 5'-CTGGATAGCCTTTCTTCTGCTG-3'; Itgax Rev, 5'-GCACACTGTGTCCGAACTC-3'; Mgl1 For, 5'-TGAGAAAGGCTTTAAGAACTGGG-3'; Mgl1 Rev, 5'-GACCACCTGTAGTGATGTGGG-3'; Mrc2 For, 5'-TACAGCTCCACGCTATGGATT-3'; Mrc2 Rev, 5'-CACTCTCCCAGTTGAGGTACT-3'; Mgl2 For, 5'-TTAGCCAATGTGCTTAGCTGG-3'; Mgl2 Rev, 5'-GGCCTCCAATTCTTGAAACCT-3'; Nos2 For, 5'-CCAAGCCCTCACCTACTTCC-3'; Nos2 Rev, 5'-CTCTGAGGGCTGACACAAGG-3'; Pparg For, 5'-GGAAGACCACTCGCATTCCTT-3'; Pparg Rev, 5'-TCGCACTTTGGTATTCTTGGAG-3'; Tnfa For, 5'-ACGGCATGGATCTCAAAGAC-3'; Tnfa Rev, 5'-AGATAGCAAATCGGCTGACG-3'. Relative expression was assessed by the comparative $\mathrm{C}_{\mathrm{T}}$ method correcting for amplification efficiency of the primers and performed in triplicate.

Immunoblotting and immunoprecipitation. Cell lysates were prepared by the addition of lysis buffer $(150 \mathrm{mM}$ sodium chloride, $50 \mathrm{mM}$ Tris $\mathrm{pH} 8,1 \%$ NP-40, $0.1 \%$ SDS, $0.5 \%$ sodium deoxycholate, $1 \mathrm{mM}$ EDTA, $10 \mathrm{mM}$ sodium fluoride, $1 \mathrm{mM}$ sodium pyrophosphate, $1 \mathrm{mM}$ sodium orthovanadate, and protease inhibitors [complete Mini tablets; Roche Applied Science]). Cells were lysed at $4{ }^{\circ} \mathrm{C}$ for 30 minutes and clarified by centrifugation. For immunoprecipitations, lysates were incubated with $1 \mu \mathrm{g}$ of anti-IRS 1 antibodies overnight at $4^{\circ} \mathrm{C}$ and immune complexes precipitated with Protein A/G-conjugated beads (Santa Cruz Biotechnology Inc.). Beads were washed with lysis buffer and resuspended in sample buffer. Lysates and immune complexes were separated by SDS-PAGE, transferred to nitrocellulose, and immunoblotted with primary antibodies followed by species-specific HRP-conjugated secondary antibodies. HRP activity was detected by chemiluminescence.

Immunohistochemistry. Formalin-fixed paraffin-embedded adipose tissue sections were deparaffinized and rehydrated prior to antigen unmasking by boiling in $10 \mathrm{mM}$ sodium citrate, $\mathrm{pH} 6.0$, with $0.05 \%$ Tween- 20 for 30 minutes. Sections were blocked in normal serum and incubated with pri- mary antibodies for durations of 1 hour to overnight. Endogenous HRP activity was quenched with incubation with $3 \%$ hydrogen peroxide for 10 minutes. Secondary antibody staining was performed using the VECTASTAIN ABC kit (Vector Laboratories) and detected with 3,3'-diaminobenzidine (DAB). Sections were counterstained with hematoxylin prior to dehydration and coverslip placement.

2-Deoxyglucose uptake assay. Adipocytes were starved in low-glucose DMEM with $0.5 \%$ serum for 3 hours prior to insulin stimulation. 2-Deoxyglucose uptake assays were performed as previously described (51).

Arginase assay. Arginase activity assays were performed as previously described (52). Briefly, cells were lysed in $0.1 \%$ Triton X-100. Tris- $\mathrm{HCl}$ was added to $12.5-\mathrm{mM}$ and $\mathrm{MnCl}_{2}$ added to $1-\mathrm{mM}$ final concentration. Arginase was activated by heating for 10 minutes at $56^{\circ} \mathrm{C}$, and L-arginine substrate was added to $250-\mathrm{mM}$ final concentration. Reactions were incubated at $37^{\circ} \mathrm{C}$ for 30 minutes and stopped by the addition of $\mathrm{H}_{2} \mathrm{SO}_{4} / \mathrm{H}_{3} \mathrm{PO}_{4}$. After addition of $\alpha$-isonitrosopropiophenone and heating for 30 minutes at $95^{\circ} \mathrm{C}$, urea production was measured by absorbance at $540 \mathrm{~nm}$ and normalized to total protein content.

$N F-\kappa B$ activation assay. 3T3-L1 adipocytes were transfected with luciferase reporter plasmid pBIIX-luc (containing 2 tandemly repeated NF-кB binding sites) along with Renilla luciferase control (100:1; Promega) as previously described (51). Twenty-four hours after transfection, cells were treated with vehicle or TNF- $\alpha(1 \mathrm{nM})$ with or without IL-10 $(20 \mathrm{ng} / \mathrm{ml})$ for 16 hours prior to lysis and analysis using the Dual-Luciferase Reporter Assay System (Promega). Values were normalized to Renilla activities.

Statistics. Results are presented as the mean \pm 1 SD. Statistical analyses were conducted using an unpaired 2-tailed Student's $t$ test, with significance set at a $P$ value of less than 0.05 .

\section{Acknowledgments}

We thank the University of Michigan Immunology Core for help with ELISA assays and the University of Michigan Flow Cytometry Core for their assistance with FACS analysis. We thank Jiande Lin for technical assistance with real-time PCR and Steven Kunkel for providing CCR2KO mice. We also thank Steve Weiss for his reading of the manuscript and helpful comments. C.N. Lumeng was supported by a training grant (T32 HD 007513-07) and a Child Health Research Career Development Award (K12 HD028820-15) from the NIH to the Department of Pediatrics and Communicable Diseases. The research was funded by a grant from the NIH (R01DK60591) to A.R. Saltiel.

Received for publication July 27, 2006, and accepted in revised form October 5, 2006.

Address correspondence to: Alan R. Saltiel, Life Sciences Institute, 210 Washtenaw Ave., Ann Arbor, Michigan 48109, USA. Phone: (734) 615-9787; Fax: (734) 763-6492; E-mail: saltiel@lsi.umich.edu.
1. Greenberg, A.S., and Obin, M.S. 2006. Obesity and the role of adipose tissue in inflammation and metabolism. Am. J. Clin. Nutr. 83:461S-465S.

2. Shoelson, S.E., Lee, J., and Goldfine, A.B. 2006. Inflammation and insulin resistance. J. Clin. Invest. 116:1793-1801. doi:10.1172/JCI29069.

3. Neels, J.G., and Olefsky, J.M. 2006. Inflamed fat: what starts the fire? J. Clin. Invest. 116:33-35. doi:10.1172/JCI27280.

4. Cancello, R., et al. 2005. Reduction of macrophage infiltration and chemoattractant gene expression changes in white adipose tissue of morbidly obese subjects after surgery-induced weight loss. Diabetes. 54:2277-2286.
5. Weisberg, S.P., et al. 2003. Obesity is associated with macrophage accumulation in adipose tissue. J. Clin. Invest. 112:1796-1808. doi:10.1172/ JCI200319246.

6. Xu, H., et al. 2003. Chronic inflammation in fat plays a crucial role in the development of obesity-related insulin resistance. J. Clin. Invest. 112:1821-1830. doi:10.1172/JCI200319451.

7. Cancello, R., et al. 2006. Increased infiltration of macrophages in omental adipose tissue is associated with marked hepatic lesions in morbid human obesity. Diabetes. 55:1554-1561.

8. Harkins, J.M., et al. 2004. Expression of interleukin- 6 is greater in preadipocytes than in adipocytes of 3T3-L1 cells and C57BL/6J and ob/ob mice. J. Nutr. 134:2673-2677.

9. Kanda, H., et al. 2006. MCP-1 contributes to macrophage infiltration into adipose tissue, insulin resistance, and hepatic steatosis in obesity. J. Clin. Invest. 116:1494-1505. doi:10.1172/JCI26498.

10. Weisberg, S.P., et al. 2005. CCR2 modulates inflammatory and metabolic effects of high-fat feeding. J. Clin. Invest. 116:115-124. doi:10.1172/JCI24335.

11. Kamei, N., et al. 2006. Overexpression of MCP-1 in adipose tissues causes macrophage recruitment and insulin resistance. J. Biol. Chem. 281:26602-26614.

12. Arkan, M.C., et al. 2005. IKK-beta links inflammation to obesity-induced insulin resistance. Nat. Med. 
11:191-198.

13. Gordon, S., and Taylor, P.R. 2005. Monocyte and macrophage heterogeneity. Nat. Rev. Immunol. 5:953-964.

14. Mantovani, A., et al. 2004. The chemokine system in diverse forms of macrophage activation and polarization. Trends Immunol. 25:677-686.

15. Gordon, S. 2003. Alternative activation of macrophages. Nat. Rev. Immunol. 3:23-35.

16. Bronte, V., and Zanovello, P. 2005. Regulation of immune responses by L-arginine metabolism. Nat. Rev. Immunol. 5:641-654.

17. Dupasquier, M., et al. 2006. The dermal microenvironment induces the expression of the alternative activation marker CD301/mMGL in mononuclear phagocytes, independent of IL-4/IL-13 signaling. J. Leukoc. Biol. 80:838-849.

18. Vats, D., et al. 2006. Oxidative metabolism and PGC-1beta attenuate macrophage-mediated inflammation. Cell Metab. 4:13-24.

19. Tacke, F., and Randolph, G.J. 2006. Migratory fate and differentiation of blood monocyte subsets. Immunobiology. 211:609-618.

20. Geissmann, F., Jung, S., and Littman, D.R. 2003. Blood monocytes consist of two principal subsets with distinct migratory properties. Immunity. 19:71-82.

21. Sunderkotter, C., et al. 2004. Subpopulations of mouse blood monocytes differ in maturation stage and inflammatory response. J. Immunol. 172:4410-4417.

22. Barzilai, N., et al. 1999. Decreased visceral adiposity accounts for leptin effect on hepatic but not peripheral insulin action. Am. J. Physiol. 277:E291-E298.

23. Raes, G., et al. 2005. Macrophage galactose-type C-type lectins as novel markers for alternatively activated macrophages elicited by parasitic infections and allergic airway inflammation. J. Lenkoc. Biol. 77:321-327.

24. Williams, L., Bradley, L., Smith, A., and Foxwell, B. 2004. Signal transducer and activator of transcription 3 is the dominant mediator of the anti-inflammatory effects of IL-10 in human macrophages. J. Immunol. 172:567-576.

25. Zhou, J.H., et al. 2001. IL-10 inhibits apoptosis of promyeloid cells by activating insulin receptor substrate-2 and phosphatidylinositol 3'-kinase. J. Immunol. 167:4436-4442.

26. Williams, L.M., Ricchetti, G., Sarma, U., Smallie, T., and Foxwell, B.M. 2004. Interleukin-10 suppression of myeloid cell activation - a continuing puzzle. Immunology. 113:281-292.

27. Dahlman, I., et al. 2005. A unique role of monocyte chemoattractant protein 1 among chemokines in adipose tissue of obese subjects. J. Clin. Endocrinol. Metab. 90:5834-5840.

28. Schottelius, A.J., Mayo, M.W., Sartor, R.B., and Baldwin, A.S., Jr. 1999. Interleukin-10 signaling blocks inhibitor of kappaB kinase activity and nuclear factor kappaB DNA binding. J. Biol. Chem. 274:31868-31874

29. Murray, P.J. 2005. The primary mechanism of the IL-10-regulated antiinflammatory response is to selectively inhibit transcription. Proc. Natl. Acad. Sci.U. S. A. 102:8686-8691.

30. Stephens, J.M., Lee, J., and Pilch, P.F. 1997. Tumor necrosis factor-alpha-induced insulin resistance in 3T3-L1 adipocytes is accompanied by a loss of insulin receptor substrate-1 and GLUT4 expression without a loss of insulin receptor-mediated signal transduction. J. Biol. Chem. 272:971-976.

31. Lumeng, C.N., DeYoung, S.M., and Saltiel, A.R. 2006. Macrophages block insulin action in adipocytes by altering expression of signaling and glucose transport proteins. Am. J. Physiol. Endocrinol. Metab. doi:10.1152/ajpendo.00284.2006.

32. Bruun, J.M., Helge, J.W., Richelsen, B., and Stallknecht, B. 2006. Diet and exercise reduce lowgrade inflammation and macrophage infiltration in adipose tissue but not in skeletal muscle in severely obese subjects. Am. J. Physiol. Endocrinol. Metab. 290:E961-E967.

33. Stout, R.D., and Suttles, J. 2004. Functional plasticity of macrophages: reversible adaptation to changing microenvironments. J. Leukoc. Biol. 76:509-513.

34. Mantovani, A., Sozzani, S., Locati, M., Allavena, P., and Sica, A. 2002. Macrophage polarization tumor-associated macrophages as a paradigm for polarized M2 mononuclear phagocytes. Trends Immunol. 23:549-555

35. Kim, H.J., et al. 2004. Differential effects of interleukin- 6 and -10 on skeletal muscle and liver insulin action in vivo. Diabetes. 53:1060-1067.

36. Bluher, M., et al. 2005. Association of interleukin-6, C-reactive protein, interleukin-10 and adiponectin plasma concentrations with measures of obesity, insulin sensitivity and glucose metabolism. Exp. Clin. Endocrinol. Diabetes. 113:534-537.

37. Oberbach, A., et al. 2006. Effect of a 4 week physical training program on plasma concentrations of inflammatory markers in patients with abnormal glucose tolerance. Eur. J. Endocrinol. 154:577-585.

38. Scarpelli, D., et al. 2006. Variants of the interleukin10 promoter gene are associated with obesity and insulin resistance but not type 2 diabetes in Cauca- sian Italian subjects. Diabetes. 55:1529-1533.

39. Wolf, A.M., Wolf, D., Rumpold, H., Enrich, B., and Tilg, H. 2004. Adiponectin induces the anti-inflammatory cytokines IL-10 and IL-1RA in human leukocytes. Biochem. Biophys. Res. Commun. 323:630-635.

40. Juge-Aubry, C.E., et al. 2005. Adipose tissue is a regulated source of interleukin-10. Cytokine. 29:270-274.

41. Soos, T.J., et al. 2006. CX3CR1+ interstitial dendritic cells form a contiguous network throughout the entire kidney. Kidney Int. 70:591-596.

42. Lumeng, C.N., Bodzin, J.L., Deyoung, S.M., and Saltiel, A.R. 2006. Increased inflammatory properties of adipose tissue macrophages recruited during diet induced obesity. Diabetes. In press.

43. Van Ginderachter, J.A., et al. 2006. Peroxisome proliferator-activated receptor gamma (PPARgamma) ligands reverse CTL suppression by alternatively activated (M2) macrophages in cancer. Blood. 108:525-535.

44. Katakura, T., Miyazaki, M., Kobayashi, M., Herndon, D.N., and Suzuki, F. 2004. CCL17 and IL-10 as effectors that enable alternatively activated macrophages to inhibit the generation of classically activated macrophages. J. Immunol. 172:1407-1413.

45. Lee, J.Y., Sohn, K.H., Rhee, S.H., and Hwang, D. 2001 Saturated fatty acids, but not unsaturated fatty acids, induce the expression of cyclooxygenase- 2 mediated through Toll-like receptor 4. J. Biol. Chem. 276:16683-16689.

46. Boschmann, M., et al. 2005. Adipose tissue metabolism and CD11b expression on monocytes in obese hypertensives. Hypertension. 46:130-136.

47. Ghanim, H., et al. 2004. Circulating mononuclear cells in the obese are in a proinflammatory state. Circulation. 110:1564-1571.

48. Stout, R.D., et al. 2005. Macrophages sequentially change their functional phenotype in response to changes in microenvironmental influences. J. Immunol. 175:342-349.

49. Park-Min, K.H., Antoniv, T.T., and Ivashkiv, L.B. 2005. Regulation of macrophage phenotype by long-term exposure to IL-10. Immunobiology. 210:77-86

50. Baumann, C.A., et al. 2000. CAP defines a second signalling pathway required for insulin-stimulated glucose transport. Nature. 407:202-207.

51. Inoue, M., Chiang, S.H., Chang, L., Chen, X.W. and Saltiel, A.R. 2006. Compartmentalization of the exocyst complex in lipid rafts controls Glut4 vesicle tethering. Mol. Biol. Cell. 17:2303-2311.

52. Munder, M., et al. 1999. Th1/Th2-regulated expression of arginase isoforms in murine macrophages and dendritic cells. J. Immunol. 163:3771-3777. 